\title{
Critérios de sustentabilidade para contratações públicas federais de empresas prestadoras de serviços de controle de pragas: uma proposta baseada em revisão de literatura
}

\section{Carlos Alberto Soares Cunha}

Instituto Nacional da Propriedade Industrial. Coordenação Geral de Administração. Rua Mayrink Veiga, 9, 24ㅇaㅁ andar. Centro. Rio de Janeiro-RJ, Brasil (CEP 20090910). E-mail: casccunha@yahoo.com.

Resumo. A exigência do cumprimento de critérios de sustentabilidade, desde muito tempo, vem se tornando mais presente nas contratações de serviços em licitações públicas, principalmente nas emanadas pelos órgãos que fazem parte do Governo Federal. Isso se dá em razão de o governo possuir, como função primordial, a característica de impulsionar, mesmo que indiretamente, o desenvolvimento social sem prejuízo ao meio ambiente garantindo, assim, melhores condições de vida para os cidadãos brasileiros. Assim, pode-se afirmar que o termo sustentabilidade foi introduzido propriamente em suas normas legais, sendo este termo um dos requisitos e critérios a constar obrigatoriamente em suas contratações. Diante do exposto, surgiu a necessidade de se proporem critérios baseados em revisão de literatura possibilitando, desta forma, a utilização destes nos termos de referência de contratações.

Palavras-chave: Critérios de sustentabilidade; Contratações; Serviços; Licitações; Governo.

\begin{abstract}
Sustainability criteria for federal public hirings of pest control service companies: A proposal based on literature review. The requirement of compliance with sustainability criteria has long been becoming more present in the contracting of services in public tenders, especially those issued by agencies that are part of the Federal Government. This is due to the fact that the government has, as its main function, the characteristic of boosting, even if indirectly, social development without damaging the environment, thus ensuring better living conditions for Brazilian citizens. Thus, it can be said that the term sustainability was properly introduced in its legal norms, this term being one of the requirements and criteria to be compulsorily included in its contracting. In view of the above, the need arose to propose criteria based on a literature review, thus enabling the use of these in the terms of reference of public contracts.
\end{abstract}

Recebido

$14 / 09 / 2021$

Aceito

$15 / 12 / 2021$

Publicado

$31 / 12 / 2021$

Acesso aberto

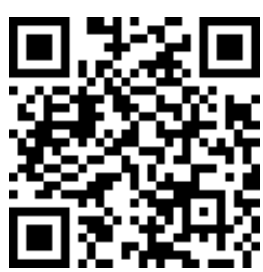

ORCID

(D) 0000-0002-6018-2999 Carlos Alberto Soares Cunha

ISSN 2359-1412/RBGAS-2021-0118/2021/8/20/24/1649

Rev. Bras. Gest. Amb. Sustent.

http://revista.ecogestaobrasil.net 
Keywords: Sustainability criteria; Contracting; Services; Tenders; Government.

\section{Introdução}

Retornando em aproximadamente cinquenta anos na linha do tempo, de acordo com Portillo (2010), diversos estudos realizados nessa época começaram a apontar para a questão do impacto ambiental do crescimento exponencial, não só da população, mas também de outros fatores como a produção industrial. Considerado como o principal exemplo desta vertente, o relatório "Os limites do crescimento", elaborado pelo Clube de Roma e publicado em 1972, considerava que, se as tendências de crescimento de cinco fatores - população mundial, produção agrícola, exaustão de recursos naturais, produção industrial e poluição - se mantivessem, os limites do crescimento do planeta seriam atingidos dentro de cem anos.

Diversas outras manifestações surgiram também a partir do Clube de Roma, inclusive podendo-se destacar o surgimento do conceito de desenvolvimento sustentável através da realização da União Internacional para a Conservação da Natureza - década de 1980. Entretanto, cabe destacar que o termo "desenvolvimento sustentável" é formalizado, pela primeira vez, por meio do Relatório de Brundtland (CMMAD, 1992), pelo qual arriscamos afirmar que o passo inicial que levou a grande maioria das entidades e corporações, privadas e públicas, a se preocuparem atualmente com a racionalização dos recursos e a diminuição dos impactos ao meio ambiente se deu com a introdução do conceito de sustentabilidade delineado pela Comissão sobre o Meio Ambiente e o Desenvolvimento por meio do Relatório de Brundtland, intitulado de Nosso Futuro Comum (Our Common Future): "O desenvolvimento que satisfaz as necessidades presentes, sem comprometer a capacidade das gerações futuras de suprir suas próprias necessidades" (CMMAD, 1992).

Ainda segundo Portillo (2010), causando grande influência no pensamento ambientalista internacional, a proposta de desenvolvimento sustentável foi rapidamente incorporada por ambientalistas de diversas tendências. Apesar das ambiguidades e desacordos, a força político-ideológica do termo ganhou cada vez mais evidência até que, a partir do fim dos anos 1980, foi adotado principalmente como um estilo de gestão empresarial.

Outro ponto importante a ser citado nesta cronologia é o da contribuição dada pelo Factor 10 Club. Segundo Wizsäcker et al. (1998), o Factor 10 Club, grupo composto por proeminentes especialistas em meio ambiente, declarou que uma melhoria dez vezes maior na produtividade material e energética nos países industrializados é tanto possível nos próximos trinta ou quarenta anos quanto necessária para um desenvolvimento sustentável e equitativo para o mundo como um todo. Isso estimulou organizações governamentais e intergovernamentais a pensar seriamente sobre a necessidade de mudanças radicais no consumo, além de provocar um debate sobre a viabilidade de tais melhorias de eficiência e sobre seu potencial impacto ambiental e econômico.

Assim, é cabível afirmar que as entidades, tanto privadas como públicas, vêm tornando-se mais cuidadosas no que tange a assuntos de cunho sustentável em suas contratações e/ou no desempenho de suas atividades empresariais acarretando, por conseguinte, a um maior zelo quanto ao consumo sustentável.

Cumpre acrescer ao exposto, conforme ensina Alves (2016), que o governo tem um papel importante nos mercados, dado seu poder de criação e regulamentação de leis. Logo, a introdução da sustentabilidade pelo Governo Federal no Brasil não seria surpresa de se esperar. 
Assim, em termos de legislação nacional, Fiorillo (2009) refere que desde a publicação da Lei n.o 4.717/1965 (Brasil, 1965), que regulamentava a ação popular, conta com a defesa dos direitos metaindividuais, a qual definia que qualquer cidadão será parte legítima para pleitear a anulação ou a declaração de nulidade de atos lesivos ao patrimônio da União etc. Outras leis seguiram a esta, tal como a Lei no 6.938/1981 (Brasil, 1981), que dispõe sobre a Política Nacional do Meio Ambiente, seus fins e mecanismos de formulação e aplicação, e dá outras providências, e a Lei no 7.347/1985, que disciplina a Ação Civil Pública de responsabilidade por danos causados ao meio ambiente, ao consumidor, a bens e direitos de valor artístico, estético, histórico, turístico e paisagístico e dá outras providências.

Cumpre acrescentar que, em termos de carta constitucional, segundo Baumgarten (2008), a Constituição de 1988 (Brasil, 1988), no que se refere às questões ambientais, está diretamente articulada ao Relatório Brundtland, assim como, a Conferência das Nações Unidas sobre o Meio Ambiente e Desenvolvimento (Rio'92) e a Agenda 21 são, também, desenvolvimentos do trabalho da Comissão liderada por Gro Brundtland.

Considerando que a cobrança de práticas e critérios sustentáveis vem se firmando e se consolidando ao longo dos anos através da exigência em vários normativos legais a ser adotada pela Administração Pública Federal, a qual se comprova através das minutas de Termos de Referência expedidos pela Advocacia-Geral da União (AGU), a situação problema deste artigo se resume a estabelecer e relacionar alguns critérios de sustentabilidade para serem exigidos na contratação de serviços continuados sem dedicação de mão de obra exclusiva que envolvam serviços de desinsetização (controle de pragas e vetores), nos termos de referência elaborados a partir da vigência da Instrução Normativa no $05 / 2017$, pelo fato de a natureza e os resíduos (embalagens descartadas etc.) de tais serviços, dependendo do material a ser utilizado, possuir alto poder de impacto ao meio ambiente.

Cumpre salientar que durante a revisão da literatura acadêmica, objetivou-se limitar à consulta nas bases Scielo, Capes e Google Acadêmico, bem como também houve necessidade de se pesquisar itens que não se comprometessem, quando da implantação, os orçamentos por parte das empresas, uma vez que a grande parte das pessoas jurídicas contratadas pela administração pública está sob o regime EIRELI ou LTDA.

0 presente artigo a visa a estabelecer critérios de sustentabilidade que possam ser exigidos nos instrumentos convocatórios (termo de referência) quando da contratação de empresas por órgãos públicos através de licitação, sem que estes impeçam a contratação de micro e pequenas empresas prestadoras de serviço.

\section{Referencial teórico}

Segundo Andrade (2009), previamente à realização do pregão em quaisquer de suas formas, a exemplo do projeto básico, o setor requisitante deve elaborar o termo de referência, com indicação precisa, suficiente e clara do objeto, sendo vedadas as especificações que, por excessivas, irrelevantes ou desnecessárias, limitem ou frustrem a competição ou sua realização.

O Decreto no 3.555/2000 (Brasil, 2000) estabelece em seu artigo 8o, inciso II:

II - o termo de referência é o documento que deverá conter elementos capazes de propiciar a avaliação do custo pela Administração, diante de orçamento detalhado, considerando os preços praticados no mercado, a definição dos métodos, a estratégia de suprimento e o prazo de execução do contrato. 
O Decreto no 10.024/2019 (Brasil, 2009) informa que:

\section{Art. 3. [...]}

$\mathrm{XI}$ - termo de referência - documento elaborado com base nos estudos técnicos preliminares, que deverá conter:

a) os elementos que embasam a avaliação do custo pela administração pública, a partir dos padrões de desempenho e qualidade estabelecidos e das condições de entrega do objeto, com as seguintes informações:

1. a definição do objeto contratual e dos métodos para a sua execução, vedadas especificações excessivas, irrelevantes ou desnecessárias, que limitem ou frustrem a competição ou a realização do certame;

2. o valor estimado do objeto da licitação demonstrado em planilhas, de acordo com o preço de mercado; e

3. o cronograma físico-financeiro, se necessário;

b) o critério de aceitação do objeto;

c) os deveres do contratado e do contratante;

d) a relação dos documentos essenciais à verificação da qualificação técnica e econômico-financeira, se necessária;

e) os procedimentos de fiscalização e gerenciamento do contrato ou da ata de registro de preços;

f) o prazo para execução do contrato; e

g) as sanções previstas de forma objetiva, suficiente e clara.

Como exposto, os elementos necessários à contratação deverão estar contemplados no termo de referência. Assim como os demais, a presença de requisitos de sustentabilidade se faz necessária.

De acordo com Gasparini (2009), a utilização do pregão, em qualquer das esferas administrativas, estará sempre restrita à aquisição de bem comum ou à contratação de serviço comum. 0 parágrafo único do art. 1ํㅡ da Lei Federal do Pregão estabelece que "Consideram-se bens e serviços comuns, para os fins e efeitos deste artigo, aqueles cujos padrões de desempenho e qualidade possam ser objetivamente definidos pelo edital, por meio de especificações usuais no mercado". Essa definição, tal qual a consignada pelas medidas provisórias anteriores, não satisfaz, e tanto isso é verdade que o Decreto $\mathrm{n}^{\mathrm{o}}$ 3.555/2000 (Brasil, 2000), traz em seu Anexo II uma lista exemplificativa de bens e serviços comuns.

Rodrigues (2003), com apoio em Silvio M. Marcondes Machado, afirma que "bens são coisas que por serem úteis e raras, são suscetíveis de apropriação e contêm valor econômico", enquanto a Lei Federal das Licitações e Contratos da Administração Pública no inciso II, do art. 60, prescreve que serviço é toda atividade destinada a obter determinada utilidade de interesse para a Administração. São essas as coisas que precisam ser comuns para que possam ser objeto de pregão.

Justen Filho (2005), depois de pertinentes considerações a respeito desse tema, define bem ou serviço comum como "aquele que apresenta sob identidade e características padronizadas e que se encontra disponível, a qualquer tempo, num mercado próprio". Gasparini (2009) ainda afirma parecer, sempre, que o bem ou o serviço desejado pela Administração Pública que for identificável pelo nome usual de mercado pode-se afirmar tratar-se de bem ou serviço comum. Com essa característica contam-se, entre outros bens: água mineral, gasolina, botijão de gás, óleo combustível, caneta 
esferográfica, papel almaço com pauta. Por sua vez, são, por exemplo, serviços comuns: limpeza de sanitários públicos, pintura de guias, digitação do manuscrito de um livro, transporte de valores.

Em todos esses exemplos nada mais é exigido para a qualificação do bem ou serviço como comum, senão o nome usual de mercado. Mercado naturalmente deve ser o meio ou setor da economia onde o bem ou o serviço está à disposição do interessado e é conhecido pelo seu nome por todos que nele militam. Embora à primeira vista possa parecer estranho, diga-se que assim devem ser considerados os bens estruturalmente complexos, como é o caso e um microcomputador de mesa, uma televisão ou uma geladeira, se por seu nome, modelo e especificações técnicas poderem ser facilmente identificados nos respectivos mercados de informática e de eletrodomésticos. Portanto, a noção de comum não está na estrutura simples do bem; nem a estrutura complexa é razão suficiente para retirar do bem sua qualificação de bem comum.

Por fim, o Tribunal de Contas da União (TCU, 2010) informa que bens e serviços comuns são produtos cuja escolha pode ser feita tão-somente com base nos preços ofertados, haja vista serem comparáveis entre si e não necessitarem de avaliação minuciosa. São encontráveis facilmente no mercado.

O bem ou o serviço será comum quando for possível estabelecer, para efeito de julgamento das propostas, mediante especificações utilizadas no mercado, padrões de qualidade e desempenho peculiares ao objeto.

Assim, resumindo o que estabelece o TCU:

Consideram-se bens e serviços comuns aqueles cujos padrões de desempenho e qualidade possam ser objetivamente definidos no edital, por meio de especificações usuais praticadas no mercado. Bens e serviços comuns são ofertados, em princípio, por muitos fornecedores e comparáveis entre si com facilidade.

Concernente ao tipo de serviço escolhido para análise contida no presente artigo achou-se mais adequado utilizar os serviços de desinsetização, pois estes lidam com questões sanitárias, como pode ser constatado no item 5.5, da Portaria ANVISA no 09/2000 (ANVISA, 2000), onde é imprescindível atentar para questões de sustentabilidade tendo em vista os impactos que podem ocasionar quando praticada forma equivocada de execução, ou seja, sem nenhum critério de sustentabilidade a ser respeitado ou observado.

\section{Sustentabilidade}

Segundo Boff et al. (2013), sustentabilidade é a palavra da moda. Tudo que é sustentável apresenta valor agregado, inclusive econômico. Está intimamente ligada ao "politicamente correto". As empresas, os governos e as pessoas precisam adotar modos sustentáveis, mas, afinal, o que é sustentabilidade mesmo?

Segundo Teixeira (2004), a palavra "sustentável" pode expressar algo "capaz de se manter mais ou menos constante, ou estável, por um longo período." Já "sustentabilidade", numa definição primária, pode ser entendida como uma qualidade de "sustentável". No começo da década de 1980, Lester Brown, fundador da Worldwatch Institute e atual presidente do Earth Policy Institute, introduziu um novo conceito sobre a palavra, a partir da visão de que uma comunidade sustentável seria aquela capaz de satisfazer às próprias necessidades sem reduzir as oportunidades das gerações futuras.

Igualmente, Teixeira (2004) informa ainda que a expressão "desenvolvimento sustentável" está sujeira a várias interpretações e que pensamentos e correntes das áreas ambiental e econômica acreditam que as palavras "desenvolvimento" e "sustentável" seriam incompatíveis na tentativa de transmitir uma ideia conjunta por serem, 
teoricamente, contraditórias em relação à evolução humana e preservação/conservação do meio ambiente.

Por fim, Teixeira (2004) afirma que quando nos remetemos à questão ambiental, entendemos as palavras "sustentável" e "sustentabilidade" e a expressão "desenvolvimento sustentável" como formas de expressarmos nossas convicções e preocupações a respeito da relação que temos hoje com os recursos naturais e o que resultará dessa relação para as novas gerações.

Para Boff (2012), "sustentabilidade é, em termos ecológicos, tudo o que fizermos para que um ecossistema não decaia e se arruíne". Para o autor é possível impedir que um sistema entre em colapso por meio da criação de alguns expedientes de sustentabilidade, como, por exemplo, plantar árvores na encosta da montanha, que servem de escora contra a erosão e os deslizamentos.

Deste modo, por sustentabilidade pode-se entender que é o uso de matérias existentes hoje de forma consciente e adequada para que não faltem no amanhã, ou seja, utilização dos recursos - ambientais, sociais, políticos, tecnológico, jurídicos, etc. - sem prejudicar as gerações futuras.

\section{Metodologia}

Primeiramente, foi efetuada, uma consulta às diversas legislações federais com vistas a consolidar uma lista de normas que tratam sobre o tema com vistas a pesquisar os possíveis critérios existentes.

Cumprida esta etapa, foi realizada pesquisa na literatura existente mais recente através da consulta à base da CAPES, Scielo e Google Scholar.

Desta feita, reunidas as informações acima, efetuou-se uma compilação do existente nas normas em vigor tendo sido esta juntada com critérios observados e coletados de artigos científicos.

\section{Resultado e discussão}

\section{literatura}

Levantamento dos critérios e práticas de sustentabilidade: uma revisão da

De acordo com Villac (2019), nos termos da Constituição Federal, a competência para legislar sobre normas gerais de licitações e contratações é privativa da União (art. 22, XXVII, CF).

No que tange às contratações federais, Fortes Júnior (2017) informa que o instituto da licitação na história brasileira se deu conforme apresentado na sequência contida na figura abaixo.

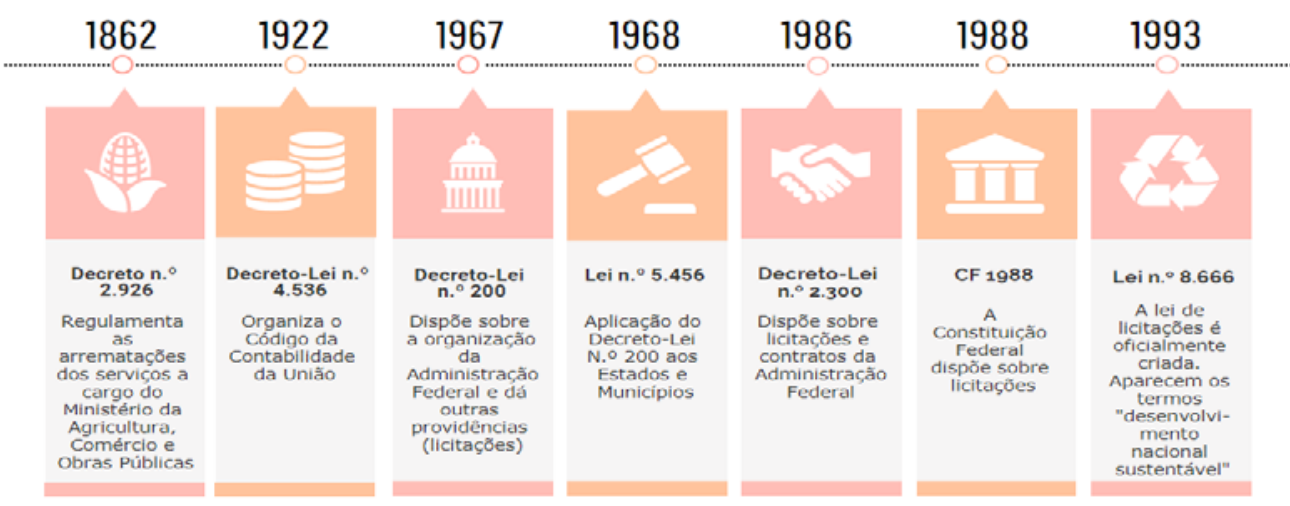

Figura 1. Breve história da licitação no Brasil. Fonte: Adaptado de Fortes Júnior, (2017). 
Como pode ser observado na Figura 1, os termos "desenvolvimento nacional sustentável" aparecem na tão famosa e importante lei de licitações (Lei n.o 8.666/93) para contratação de obras e serviços de engenharia.

Seguidamente, com o advento do Decreto no 3.555/2000, é aprovado o regulamento para a modalidade de licitação denominada pregão para aquisição de bens e serviços comuns. Com tal decreto, a Administração Pública está abarcando mais serviços os ditos comuns, a serem contratados. Entretanto, tal decreto se referia a licitações de pregões presenciais, onde era necessário que o participante estivesse presente para dar lances e atuar no certame.

Um pouco depois surge a Lei no 10.520/2002 (Brasil, 2002), que institui o pregão em si, e o Decreto no 5.450/2005, o qual estabelece o pregão na forma eletrônica, que foi substituído pelo Decreto no 10.024/2019 (Brasil, 2019).

Portanto, sob a forma eletrônica, o que o Governo Federal almejava com a criação das citadas leis e decretos seria a de abranger a maior quantidade possível de empresas participantes nas licitações com o objetivo de se obter preços mais vantajosos.

Além do exposto anteriormente, Andrade (2009) informa que um dos princípios correlatos, trazidos pela Lei no $10.520 / 2002$ foi o da Sustentabilidade Ambiental em que deve ser verificada sempre a possibilidade de impacto ambiental do produto ou serviço a ser adquirido. Assim, no caso de licitações e serviços ou produtos que causem impacto ambiental, as normas de proteção devem ser buscadas e inseridas nos editais, a fim de que se tenha uma licitação que observe os preceitos de proteção do meio ambiente.

Apesar de haver diversas leis que contemplavam a preocupação com a proteção ao meio ambiente, cumpre destacar que, segundo Villac (2019), o marco inaugural, com previsão expressa das licitações sustentáveis no ordenamento, não constou de inserção do tema por alteração na Lei de Licitações após regular processo legislativo, mas, sim, pela elaboração de norma de inferior hierarquia, emanada pelo Ministério do Planejamento, traduzindo-se em ato unilateral, sem necessidade de votação e aprovação no Congresso Nacional.

Antecedentemente, a Portaria MMA no 61/2008, por delegação, estabeleceu orientações acerca da inserção da sustentabilidade nas contratações públicas. Contudo, a aplicação da referida norma estava restrita às licitações empreendidas por aquele ministério. A iniciativa do MMA é precursora também por relacionar licitações sustentáveis com medidas de gestão pública sustentável.

Ainda segundo Villac (2019), a Instrução Normativa SLTI no 1/2010, introduziu mudanças significativas nas contratações públicas, não meramente operacionais, mas substantivas, conferindo uma inédita maneira de se considerar a licitação, que passou a necessidade de conter critérios de sustentabilidade, desde a extração até o descarte o âmbito de todo o Poder Executivo federal.

Outro ponto a destacar foi o da publicação do Decreto no 7.746/2012. Tal decreto regulamentou o art. 3ㅜㅡ, da Lei no 8.666/1993 (Brasil, 1993), para estabelecer critérios e práticas para a promoção do desenvolvimento nacional sustentável nas contratações realizadas pela administração pública federal direta, autárquica e fundacional e pelas empresas estatais dependentes, e institui a Comissão Interministerial de Sustentabilidade na Administração Pública (CISAP). Assim, o art. 2ำ dispõe que na aquisição de bens e na contratação de serviços e obras, a administração pública federal direta, autárquica e fundacional e as empresas estatais dependentes adotarão critérios e práticas sustentáveis nos instrumentos convocatórios, observado o disposto neste decreto.

Pode-se afirmar que, em decorrência das diversas instruções - evolução das citadas normas -, foi estabelecido que os Termos de Referência passassem a ter, praticamente, a mesma formação e, por conseguinte, a mesma estrutura em si (objetivos, justificativas, obrigações, requisitos etc.). Isso se evidencia nos modelos disponíveis no site da Advocacia-Geral da União (AGU) para os segmentos em que se pretende contratar: 
serviços não continuados (pregão), serviços continuados sem mão de obra exclusiva, serviços continuados com mão de obra exclusiva, serviços de manutenção predial etc.

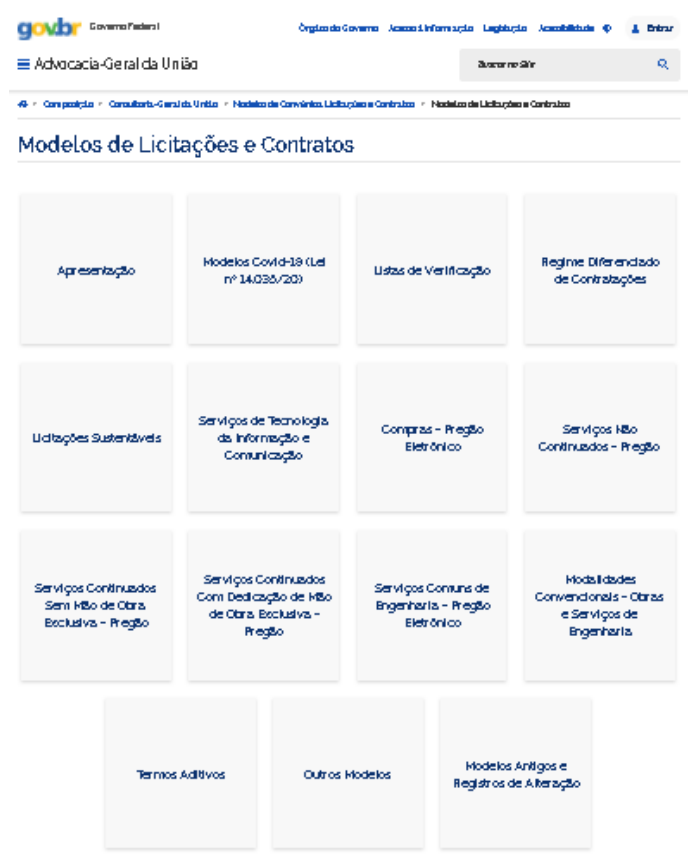

Figura 2. Modelo de licitações e contratos. Fonte: AGU (2021).

Além da padronização dos Termos de Referência, evidencia-se que critérios e práticas de sustentabilidade, conforme destacado na Figura 3, passaram a ser um dos requisitos da contratação constantes no modelo de termo de referência sugerido pela AGU, para contratação de serviços de continuados sem mão de obra exclusiva.

5. REQUISITOS DA CONTRATAÇÄO

5.1. Conforme Estudos Preliminares, os requisitos da contratação abrangem o seguinte:

5.1.1.... (requisitos necessários para o atendimento da necessidade)

5.1.2... (serviço continuado ou não)

5.1.3.... (critérios e práticas de sustentabilidade)

5.1.4.... (duração inicial do contrato)

5.1.5... (eventual necessidade de transição gradual com transferência de conhecimento, tecnologia e técnicas empregadas $\downarrow$

5.1.6.... (quadro com soluções de mercado)

5.2. Declaração do licitante de que tem pleno conhecimento das condições necessárias para a prestação do serviço. 5.3. A quantidade estimada de deslocamentos é de___. Há a necessidade de hospedagem,
estimada em

5.4. As obrigações da Contratada e Contratante estão previstas neste TR.

Figura 3. Requisitos da contratação. Fonte: AGU (2021). 
Assim sendo, como pode ser notado através da recomendação da AGU em seus modelos, os termos "critérios e práticas de sustentabilidade" se tornaram presentes nos modelos atuais no que tange à contratação de serviços com o objetivo de garantir o menor impacto ambiental possível o que vai ao encontro do que cita Lemos e Quelhas (2006) concernente à melhoria na aplicação e cobrança da obrigatoriedade da sustentabilidade:

Todos nós, governos, empresários, organizações não governamentais, sociedade civil em geral, somos responsáveis pelas mudanças que serão necessárias para iniciarmos o processo de transição em direção ao desenvolvimento sustentável.

Após exposição acima e dando continuidade à realização de consulta às legislações federais em vigor, a principal norma localizada que trata de critérios de sustentabilidade é a Instrução Normativa no 01/2010, da Secretaria de Logística e Tecnologia da Informação do Ministério do Planejamento, Orçamento e Gestão, que dispõe sobre os critérios de sustentabilidade ambiental na aquisição de bens, contratação de serviços ou obras pela Administração Pública Federal direta, autárquica e fundacional e dá outras providências.

O Capítulo III - Dos Bens e Serviços, em seu art. 6º informa:

Art. 6o Os editais para a contratação de serviços deverão prever que as empresas contratadas adotarão as seguintes práticas de sustentabilidade na execução dos serviços, quando couber:

I - use produtos de limpeza e conservação de superfícies e objetos inanimados que obedeçam às classificações e especificações determinadas pela ANVISA;

II - adote medidas para evitar o desperdício de água tratada, conforme instituído no Decreto no 48.138, de 8 de outubro de 2003;

III - observe a Resolução CONAMA no 20, de 7 de dezembro de 1994, quanto aos equipamentos de limpeza que gerem ruído no seu funcionamento;

IV - forneça aos empregados os equipamentos de segurança que se fizerem necessários, para a execução de serviços;

$\mathrm{V}$ - realize um programa interno de treinamento de seus empregados, nos três primeiros meses de execução contratual, para redução de consumo de energia elétrica, de consumo de água e redução de produção de resíduos sólidos, observadas as normas ambientais vigentes;

VI - realize a separação dos resíduos recicláveis descartados pelos órgãos e entidades da Administração Pública Federal direta, autárquica e fundacional, na fonte geradora, e a sua destinação às associações e cooperativas dos catadores de materiais recicláveis, que será procedida pela coleta seletiva do papel para reciclagem, quando couber, nos termos da IN/MARE no 6 , de 3 de novembro de 1995 e do Decreto no 5.940 , de 25 de outubro de 2006;

VII - respeite as Normas Brasileiras - NBR publicadas pela Associação Brasileira de Normas Técnicas sobre resíduos sólidos; e

VIII - preveja a destinação ambiental adequada das pilhas e baterias usadas ou inservíveis, segundo disposto na Resolução CONAMA no 257, de 30 de junho de 1999.

Parágrafo único. 0 disposto neste artigo não impede que os órgãos ou entidades contratantes estabeleçam, nos editais e contratos, a exigência de observância de outras práticas de sustentabilidade ambiental, desde que justificadamente.

Para a natureza de serviço objeto do estudo deste artigo, consideram-se aplicáveis como critérios de sustentabilidade, os quais deverão constar nos instrumentos convocatórios por força de norma, os seguintes incisos IV, V, VII (no que tange aos 
resíduos sólidos, a empresa deverá adotar as medidas mitigadoras de impacto ambiental dos resíduos sólidos, classificados conforme norma ABNT NBR 10004:2004).

Concernente ao inciso IV, cumpre destacar que o fornecimento dos equipamentos de proteção característicos aos profissionais que executam os serviços de desinsetização são fundamentais para proteção individual e coletiva, o que resta consignado que a inclusão deste se torna imprescindível.

Quanto ao inciso V, a norma em si destaca a importância de a empresa possuir um programa de treinamento interno para seus empregados com vistas à redução de energia elétrica, de consumo de água e redução de resíduos sólidos. Uma vez que o inciso revela a importância do treinamento para redução de energia, água e outros, acredita-se que este possa ser complementado com ações de redução de consumo de copos plásticos descartáveis, utilização de transportes solidário etc.

No que se refere ao inciso VII, a ABNT NBR 10004:2004 (ABNT, 2004) define os resíduos sólidos como "resíduos nos estados sólido e semissólido, que resultam de atividades de origem industrial, doméstica, hospitalar, comercial, agrícola, de serviços e de varrição. Ficam incluídos nesta definição os lodos provenientes de sistemas de tratamento de água, aqueles gerados em equipamentos e instalações de controle de poluição, bem como determinados líquidos cujas particularidades tornem inviável o seu lançamento na rede pública de esgotos ou corpos de água, ou exijam para isso soluções técnica e economicamente inviáveis em face à melhor tecnologia disponível.

Estabelecida a definição, há de se levar em conta também, conforme norma: a periculosidade de um resíduo (risco à saúde pública e risco ao meio ambiente), a toxicidade, o agente tóxico, a toxicidade aguda, o agente teratogênico, o agente mutagênico, o agente carcinogênico e o agente ecotóxico (substâncias ou misturas que apresentem ou possam apresentar riscos para um ou vários compartimentos ambientais).

Assim, entende-se que a empresa deverá adotar medidas adequadas no tratamento de resíduos que possam acarretar em riscos/danos ao meio ambiente, bem como se estes possuam características de inflamabilidade, corrosividade, reatividade, toxicidade e patogenicidade) ou cujos produtos de combate de vetores e pragas possuam constituintes perigosos e que estejam relacionados no Anexo B ao E.

0 parágrafo único, do art. 6º, da Instrução Normativa no 01/2010 permite, desde que justificadamente, que os órgãos ou entidades contratantes estabeleçam, nos editais e contratos, a exigência de observância de outras práticas de sustentabilidade ambiental. Desta maneira, quanto aos critérios que não estão englobados em legislações em vigor, buscou-se complementá-los com informações oriundas de artigos científicos, dissertações e/ou teses.

Isto posto, o primeiro critério que pode ser proposto é que a empresa faça uso, nos escritórios de sua matriz e filial, de lâmpadas LED (Light-Emitting Diode) ao invés das lâmpadas convencionais. A comprovação da utilização poderá ser feita através de declaração fornecida pela empresa quando do envio da proposta de preços relativa à licitação na qual esta esteja participando.

Segundo Santos et al. (2015), a lâmpada de LED mostrou-se mais econômica quando comparada com as lâmpadas comumente usadas nas residências e indústrias do Brasil. É uma lâmpada relativamente cara no mercado atual, porém, como seu consumo de energia é muito menor que as demais, o retorno de investimento na troca das lâmpadas é rápido.

Ainda de acordo com o trabalho de Santos et al (2015), constatou-se que a lâmpada tem uma vida útil longa, o que garante menor troca no decorrer dos anos, além da economia na conta de energia do consumidor. Para o meio ambiente, é uma alternativa de mitigar a poluição, pois a composição da lâmpada de LED não é nociva ao meio e tem maior durabilidade, além de minimizar a quantidade de lâmpadas a serem descartadas. Já a lâmpada incandescente tem durabilidade inferior, aumentando o número de trocas e

Rev. Bras. Gest. Amb. Sustent., 2021, vol. 8, n. 20, p. 1649-1663. 
descartes, e o vidro é composto por pequenas partículas de metal, devendo ser tratado separadamente dos vidros recicláveis. A lâmpada fluorescente é composta por Mercúrio e sua descontaminação é um processo caro e demorado. Essa descontaminação se faz necessária, pois o mercúrio descartado de forma incorreta compromete a qualidade do solo e dos corpos d'água.

Desta feita, pode-se afirmar que a comprovação de utilização de lâmpadas LED nos escritórios das empresas, em substituição às demais lâmpadas, pode ser um dos critérios a ser contemplado fora dos normativos obrigatórios. Assim, seria interessante estabelecer a cobrança de uma declaração de que a empresa utiliza em sua totalidade ou em mais de 90\% (noventa por cento) a tecnologia LED em sua iluminação interna/externa.

Outro item a ser listado como critério, no instrumento de convocação da licitação, é o da existência, na empresa, de programa de "coleta seletiva" de lixo, diferentemente do presente no inciso VI, da Instrução Normativa no 01/2010, uma vez que este se refere a resíduos a serem separados no local onde está sendo executado o serviço e restrito a empresas prestadoras de serviços de limpeza.

De acordo com Morais e Colesanti (2011), a implantação da coleta seletiva de lixo é uma boa forma de unir teoria e prática ecológicas. Para ser bem sucedida, ela precisa ser acompanhada por um projeto de educação ambiental que mobilize o público alvo, em torno de palestras, seminários, cartazes e cartilhas explicativas.

Assim, segundo Morais e Colesanti (2011), o primeiro público alvo é o próprio funcionário, ou seja, a diretoria, o corpo técnico, os operários e os prestadores de serviço. Este público é o mais importante multiplicador da opinião da empresa e deve ser o alvo de seminários e campanhas de conscientização, adequadas a cada nível, que envolva a todos na mesma responsabilidade com o meio ambiente.

Estando o público alvo devidamente capacitado e ciente da responsabilidade ambiental que detêm, o programa de coleta seletiva de lixo deverá apresentar, como requisitos básicos: disposição de lixeiras coloridas de acordo com o material de coleta (papéis (cor azul), plásticos (cor vermelha), vidro (cor verde), metais (cor amarela) e orgânicos e resíduos não recicláveis (cor marrom), pilhas e baterias (cor laranja)), com seus respectivos adesivos indicando os nomes dos materiais: papel, plástico, vidro, metal, orgânicos e não recicláveis, pilhas e baterias - conforme Resolução CONAMA no 275/2001 (Brasil, 2001); possuir treinamento anual sobre o programa através de palestras, seminários e outros; possuir uma política de racionalização quanto à utilização dos recursos (água, luz papel etc.); bem como haver divulgação de políticas de conscientização para utilização de transportes coletivos etc.; estabelecer parcerias com cooperativas locais para destinação do lixo gerado pela empresa - os orgânicos e não recicláveis seriam recolhidos pela coleta urbana convencional e os demais através de acordos com cooperativas, com vistas a beneficiar pessoas locais através da venda de material reciclável.

\section{Análise e proposição de critérios decorrentes do levantamento}

Em termos de legislação, é salutar registrar que três itens se tornam obrigatórios, por força de lei, para compor o rol de critérios a serem obedecidos pelas empresas que prestam serviços de controle de pragas na licitação. Assim, tem-se:

1. Fornecer aos empregados os equipamentos de segurança (coletivo e individual), que se fizerem necessários, para a execução de serviços.

2. Realizar um programa interno de treinamento de seus empregados, nos três primeiros meses de execução contratual, para redução de consumo de energia elétrica, de consumo de água e redução de produção de resíduos sólidos, observadas as normas ambientais vigentes. 
3. Respeitar a Norma ABNT NBR 10004:2004 - Resíduos Sólidos Classificação, no que tange à destinação dos resíduos decorrentes da execução dos trabalhos de controle de pragas com o intuito de mitigar e/ou eliminar as chances de impactos ao meio ambiente.

Cumpre destacar que o item 3 foi adaptado tendo em vista a análise da norma ABNT NBR 10004:2004, a qual trata da destinação dos resíduos (químicos principalmente).

Quanto aos aspectos extralegais, em decorrência de revisão literária, chegou-se aos seguintes itens:

4. Comprovar, mediante declaração padrão a constar em edital, que a empresa faz uso em seus escritórios (matriz e filiais), em sua totalidade, de tecnologia LED em sua iluminação interna/externa.

5. Comprovar, mediante declaração, que a empresa detém de programa de coleta seletiva de lixo onde disponha de lixeiras devidamente codificadas de acordo com a Resolução Conama n. ${ }^{2}$ 275, de 25 de abril de 2001 e que possua parcerias com cooperativas locais para destinação do lixo gerado pela própria empresa;

6. Comprovar, mediante declaração, de que a empresa efetua treinamento anual cuja temática seja o programa de coleta seletiva e que possua uma política de conscientização da importância da racionalização quanto à utilização dos recursos (água, luz papel etc.).

\section{Considerações finais}

Objetivou-se com este artigo fazer uma revisão de literatura em termos legais e acadêmicos com o objetivo de propor critérios e práticas de sustentabilidade com vistas a integrarem possivelmente os instrumentos convocatórios das contratações federais e, consequentemente, garantir as boas práticas de sustentabilidade a serem executadas pelas empresas contratadas que prestam serviços de desinsetização para a Administração Pública.

Outrossim, como dito anteriormente, este estudo está limitado a propor critérios e práticas de sustentabilidade com cunho legal e acadêmico para as contratações públicas federais. Assim, salienta-se que o proposto não esgota as possibilidades relacionadas ao assunto em comento. Entretanto, estudos futuros poderão ser realizados à medida que novas legislações se tornem vigentes, bem como pelo fato de que as tecnologias que propiciam a prática da sustentabilidade nas atividades empresariais tendem a reduzir de custo ao longo do tempo.

Por fim recomenda-se que, futuramente, os critérios sejam apresentados às empresas de regime LTDA, MEI e EIRELI, através da formulação de questionários, com vistas a verificar o grau de aceitabilidade ou de propensão/conscientização para a adoção de tais práticas.

\section{Conflitos de interesses}

O autor declara não haver conflito de interesses.

\section{Referências}

ABNT - Associação Brasileira de Normas Técnicas. ABNT NBR no 10004: Resíduos Sólidos - Classificação. Rio de Janeiro: ABNT, 2004. 
AGU - Advocacia-Geral da União. Modelos de licitações e contratos. 2021. Disponível em: <https://www.gov.br/agu/pt-br/composicao/consultoria-geral-da-uniao-1/modelos-deconvenios-licitacoes-e-contratos/modelos-de-licitacoes-e-contratos>. Acesso em: 22 maio 2021.

Alves, R. R. Administração verde: o caminho sem volta da sustentabilidade ambiental nas organizações. São Paulo: Elsevier, 2016.

Andrade, W. O. Editais de licitação: técnicas de elaboração e sistema de registro de preços. Belo Horizonte: Del Rey, 2009.

Brasil. Portaria ANVISA no 09, de 16 de novembro de 2000. Disponível em: <https://aeap.org.br/wp-content/uploads/2019/10/portaria_cvs_9_de_16_ de_novembro_de_2000.pdf>. Acesso em: 23 maio 2021.

Baumgarten, M. Conhecimento e sustentabilidade: políticas de ciência, tecnologia e Inovação no Brasil contemporâneo. Porto Alegre: UFRGS/Sulina, 2008.

Boff, L. Sustentabilidade: o que é - o que não é. Rio de Janeiro: Vozes, 2012.

Boff, S. O.; Fortes, V. B.; Morais, V. B. Sustentabilidade e direitos fundamentais. Passo Fundo: IMED, 2013.

Brasil. Lei no 4.717, de 29 de junho de 1965. Regula a ação popular. Disponível em: <http://www.planalto.gov.br/ccivil_03/leis/14717.htm>. Acesso em: 18 ago. 2021.

Brasil. Lei no 6.938, de 31 de agosto de 1981. Dispõe sobre a Política Nacional do Meio Ambiente, seus fins e mecanismos de formulação e aplicação, e dá outras providências. Disponível em: <http://www.planalto.gov.br/ccivil_03/leis/16938.htm>. Acesso em: 18 ago. 2021.

Brasil. Lei no 7.347, de 24 de julho de 1985. Disciplina a ação civil pública de responsabilidade por danos causados ao meio-ambiente, ao consumidor, a bens e direitos de valor artístico, estético, histórico, turístico e paisagístico (VETADO) e dá outras providências. Disponível em: <http://www.planalto.gov.br/ccivil_03/leis/17347orig.htm>. Acesso em: 18 ago. 2021.

Brasil. Constituição da República Federativa do Brasil de 1988. Disponível em: $<$ http://www.planalto.gov.br/ccivil_03/constituicao/constituicao.htm>. Acesso em: 18 ago. 2021.

Brasil. Lei no 8.666, de 21 de junho de 1993. Regulamenta o art. 37, inciso XXI, da Constituição Federal, institui normas para licitações e contratos da Administração Pública e dá outras providências. Disponível em: <http://www.planalto.gov.br/ ccivil_03/leis/18666cons.htm>. Acesso em: 18 ago. 2021.

Brasil. Decreto no 3.555, de 8 de agosto de 2000. Aprova o Regulamento para a modalidade de licitação denominada pregão, para aquisição de bens e serviços comuns. Disponível em: <http://www.planalto.gov.br/ccivil_03/decreto/d3555.htm>. Acesso em: 18 ago. 2021.

Brasil. Lei no 10.520, de 17 de julho de 2002. Institui, no âmbito da União, Estados, Distrito Federal e Municípios, nos termos do art. 37, inciso XXI, da Constituição Federal, modalidade de licitação denominada pregão, para aquisição de bens e serviços comuns, e dá outras providências. Disponível em: <http://www.planalto.gov.br/ccivil_03/leis/ 2002/l10520.htm>. Acesso em: 18 ago. 2021. 
Brasil. Resolução CONAMA no 275, de 25 de abril de 2001. Estabelece o código de cores para os diferentes tipos de resíduos, a ser adotado na identificação de coletores e transportadores, bem como nas campanhas informativas para a coleta seletiva. Disponível em: <https://www.legisweb.com.br/legislacao/?id=97507>. Acesso em: 18 ago. 2021.

Brasil. Instrução Normativa MPOG no 01, de 19 de janeiro de 2010. Dispõe sobre os critérios de sustentabilidade ambiental na aquisição de bens, contratação de serviços ou obras pela Administração Pública Federal direta, autárquica e fundacional e dá outras providências. Disponível em: <https://www.gov.br/governodigital/pt-br/legislacao/ IN01de2010ComprasSustentaveis.pdf>. Acesso em: 18 ago. 2021.

Brasil. Decreto no 7.746, de 5 de junho de 2012. Regulamenta o art. 3o da Lei no 8.666 , de 21 de junho de 1993, para estabelecer critérios e práticas para a promoção do desenvolvimento nacional sustentável nas contratações realizadas pela administração pública federal direta, autárquica e fundacional e pelas empresas estatais dependentes, e institui a Comissão Interministerial de Sustentabilidade na Administração Pública - CISAP. (Redação dada pelo Decreto no 9.178, de 2017). Disponível em: <http://www.planalto.gov.br/ccivil_03/_ato2011-2014/2012/decreto/d7746.htm>.

Acesso em: 18 ago. 2021.

Brasil. Decreto no 10.024, de 20 de setembro de 2019. Regulamenta a licitação, na modalidade pregão, na forma eletrônica, para a aquisição de bens e a contratação de serviços comuns, incluídos os serviços comuns de engenharia, e dispõe sobre o uso da dispensa eletrônica, no âmbito da administração pública federal. Disponível em: <http://www.planalto.gov.br/ccivil_03/_ato2019-2022/2019/decreto/D10024.htm>.

Acesso em: 18 ago. 2021.

CMMAD - Comissão Mundial sobre Meio Ambiente e Desenvolvimento. Nosso futuro comum. 2. ed. Rio de Janeiro: Fundação Getúlio Vargas, 1992.

Fiorillo, C. A. P. Curso de Direito Ambiental Brasileiro. 10. ed. São Paulo: Saraiva, 2009.

Fortes Júnior, C. O. Breve história das licitações no Brasil. 2017. Disponível em: <http://www.fortesjr.com.br/breve-historia-das-licitacoes-no-brasil/>. Acesso em: 10 maio 2021.

Gasparini, C. D. Pregão presencial e eletrônico. 2. ed. rev. e ampl. Belo Horizonte: Fórum, 2009.

Justen Filho, M. Pregão: comentários à legislação do pregão comum e eletrônico. 4. ed. rev. e atual. São Paulo: Dialética, 2005.

Lemos, H. M.; Santos, C. H. Quelhas, O. L. Sustentabilidade das organizações brasileiras. Niterói: ABEPRO, 2006.

Morais, C. F.; Colesanti, M. T. M. Uma proposta para coleta seletiva: implantando a educação ambiental na empresa schincariol - Uberlândia/MG. Revista Caminhos da Geografia, v. 12, n. 38, p. 221-236, 2011.

Portillo, F. Sustentabilidade ambiental, consumo e cidadania. 2. ed. São Paulo: Cortez, 2010.

Rodrigues, S. Direito civil: parte geral. 34. ed. São Paulo: Saraiva, 2003.

Santos, T. S.; Batista, M. C.; Pozza, S. A.; Rossi, L. S. Análise da eficiência energética, ambiental e econômica entre lâmpadas de LED e convencionais. Engenharia Sanitária Ambiental, $\quad$ v. 20 , n. $4 . \quad$ p. 595-602, 2015. https://doi.org/10.1590/S141341522015020040125106 
Severino, A. J. Metodologia do trabalho científico. 23. ed. rev. e atual. São Paulo: Cortez, 2007.

Teixeira, A. C. A questão ambiental: desenvolvimento e sustentabilidade. Rio de Janeiro: FUNSEG, 2004.

TCU - Tribunal de Contas da União. Licitações e contratos: orientações e jurisprudência do TCU. 4. ed. rev., atual. e ampl. Brasília: TCU, 2010.

Villac, T. Licitações sustentáveis no Brasil: um breve ensaio sobre ética ambiental e desenvolvimento. Belo Horizonte: Fórum, 2019.

Wizsäcker, E.; Lovins, A.; Lovins, L. H. Factor four: Doubling wealth halving resource use. London: Earthsca, 1998. 